\title{
Statistical Characteristics of Raindrop Size Distribution during Rainy Seasons in Northwest China
}

\author{
Yong Zeng $\mathbb{D}^{1,2}$ Lianmei Yang, ${ }^{1,2}$ Zepeng Tong, ${ }^{1,2}$ Yufei Jiang, ${ }^{1,2}$ Zuyi Zhang, ${ }^{1,2}$ \\ Jinru Zhang, ${ }^{1,2}$ Yushu Zhou, ${ }^{3,4}$ Jiangang Li, ${ }^{1,2}$ Fan Liu, ${ }^{1,2}$ and Jin Liu ${ }^{1,2}$ \\ ${ }^{1}$ Institute of Desert Meteorology, China Meteorological Administration, Urumqi 830002, China \\ ${ }^{2}$ Center for Central Asian Atmosphere Science Research, Urumqi 830002, China \\ ${ }^{3}$ Laboratory of Cloud-Precipitation Physics and Severe Storms, Institute of Atmospheric Physics, Chinese Academy of Sciences, \\ Beijing 100029, China \\ ${ }^{4}$ College of Earth Science, University of Chinese Academy of Sciences, Beijing 100049, China
}

Correspondence should be addressed to Yong Zeng; 15099610397@163.com

Received 24 December 2020; Revised 22 February 2021; Accepted 25 February 2021; Published 8 March 2021

Academic Editor: Stefano Federico

Copyright (c) 2021 Yong Zeng et al. This is an open access article distributed under the Creative Commons Attribution License, which permits unrestricted use, distribution, and reproduction in any medium, provided the original work is properly cited.

\begin{abstract}
Raindrop size distribution (DSD) is of great significance for understanding the microphysical process of rainfall and the quantitative precipitation estimation (QPE). However, in the past, there was a lack of relevant research on Xinjiang in the arid region of northwest China. In this study, the rainy season data collected by the disdrometer in the Yining area of Xinjiang were used for more than two years, and the characteristics of DSDs for all samples, for two rain types (convective and stratiform), and for six different rain rates were studied. The results showed that nearly $70 \%$ of the total samples had a rainfall rate of less than $1 \mathrm{~mm} \cdot \mathrm{h}^{-1}$, the convective rain was neither continental nor maritime, and there was a clear boundary between convective rain and stratiform rain in terms of the scattergram of the standardized intercept parameter $\left(\log _{10} N_{w}\right)$ versus the mass-weighted average diameter $\left(D_{m}\right)$. When the raindrop diameter was less than $0.7 \mathrm{~mm}$, DSDs of the two rainfalls basically coincided, while when the raindrop diameter was greater than $0.7 \mathrm{~mm}$, DSDs of convective rainfall were located above the stratiform rain. As the rainfall rate increased, $D_{m}$ increased, while $\log _{10} N_{w}$ first increased and then decreased. In addition, we deduced the $Z-R$ (radar reflectivityrain rate) relationship and $\mu-\Lambda$ relationship (shape parameter-slope parameter of the gamma DSDs) suitable for the Yining area. These conclusions are conducive to strengthening the understanding of rainfall microphysical processes in arid regions and improving the ability of QPE in arid regions.
\end{abstract}

\section{Introduction}

Raindrop size distribution (DSD) is one of the important aspects of rainfall research, and it is very meaningful for understanding the microphysical process of rainfall and the quantitative precipitation estimation (QPE) [1-3]. A large number of studies have shown that DSDs are affected by climate types [4-6], topographical conditions [7-9], precipitation types [10-12], precipitation months [13-15], and present different characteristics.

From the tropics to mid-latitudes, many researchers have used observational data to obtain the characteristics of DSDs of different continental areas. Researchers have conducted extensive studies on Darwin in Australia [16], the Indian coast [17], South Korea [18], Taiwan [19], Singapore [20], Oklahoma [21], and south and east China [22-24], and the research conclusions are of great significance for understanding the characteristics of local DSDs and improving the level of QPEs. Some researchers have also used the observation data of ships on the ocean to obtain the characteristics of DSDs on the ocean [25-27]. Bringi et al. [28] compared the characteristics of DSDs of continental and ocean areas and pointed out that the mass-weighted average diameter $\left(D^{m}\right)$ of marine rainfall is smaller than that of continental rainfall, and the normalized intercept parameter $\left(\log 10 N^{w}\right)$ of marine rainfall is larger than that of 
continental rainfall. Ma et al. [14] pointed out that in the rainy season from May to October in Beijing, $D^{m}$ of the rainfall in July is the largest and $\log 10 \mathrm{~N}^{w}$ is the smallest. Wen et al. [13] studied DSDs in eastern China and found that the characteristics of DSDs show differences in different rainfall types and different seasons. The above-mentioned researches play a key role in fully understanding the characteristics of DSDs. However, it is clear that the past researches mainly focused on monsoon regions and humid regions, and less research on DSDs in arid regions has restricted the understanding of rainfall microphysical processes in arid regions. Simultaneously, it becomes difficult to improve the level of QPEs in arid areas.

Xinjiang is located in the central part of Asia, and far from the ocean and not directly affected by the monsoon system, so it is a typical arid climate zone [29]. The rain amount in Xinjiang is obviously lower than that in the monsoon regions of China, and the rainfall intensity is also lower than in eastern and southern China [30]. However, rainfall is of vital importance in the ecological environment, production, and life in Xinjiang [31]. In the past, the research on rainfall in Xinjiang mainly focused on the weather scale system [31], mesoscale system [32, 33], and environmental conditions of rainfall $[34,35]$, and there was a lack of research on the microphysical process of rainfall. Zeng et al. [36] used DSDs data from the spring of 2020 to study the diurnal variation characteristics of DSDs in the Xinyuan area of Xinjiang and found that the diurnal variation characteristics are related to the precipitation system, valley wind, and solar radiation. However, only the characteristics of DSDs of spring are obtained, but the research on the overall characteristics of the rainy season is lacking. This research focuses on DSDs and microphysical characteristics of rainfall during rainy seasons in Xinjiang. The conclusions of the study are conducive to strengthening the understanding of the microphysical process of rainfall in arid regions and improving the ability of QPEs in arid regions.

\section{Study Area, Data, and Methods}

2.1. Study Area. The area of this study is the Xinjiang region in northwestern China, which is also located in the northern Tibetan Plateau (Figure 1). This area is a typical arid area, with the famous Taklimakan Desert and the Gurbantungut Desert. Between the two desserts are the famous Tianshan Mountains. As the most rainfall-rich area in Xinjiang, the Tianshan Mountains are important for the regional weather and climate.

2.2. Data. The disdrometer data of this study were collected by a disdrometer of Yining Meteorological Station of Xinjiang from July 2018 to August 2020 (April to October,

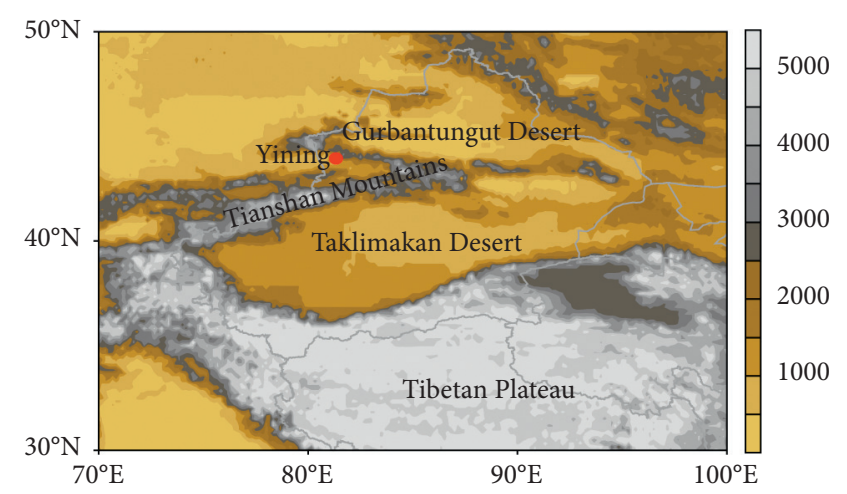

FIgURE 1: Location of the observation site (red filled circle) and the topography $(\mathrm{m})$.

November to March of the following year is mainly snowfall, regardless).The disdrometer in this study is a second-generation particle size and velocity (Parsivel) disdrometer, which was produced by the OTT Hydromet Company (Kempten, Germany). The disdrometer emits a $54 \mathrm{~cm}^{2}$ laser beam, and the disdrometer provides counts per diameter $(D)$ and velocity $(V)$ classes of the drops that have passed through the laser beam in the last minute [37]. In order to reduce the sampling error caused by insufficient raindrops and too small rainfall intensity, this study abandoned samples with raindrops less than 10 or rain intensity less than $0.1 \mathrm{~mm} \cdot \mathrm{h}^{-1}[12,26]$. Additionally, raindrops with diameters greater than $6 \mathrm{~mm}$ and fall speed of $60 \%$ above or below the Atlas et al. [38] empirical fall velocity-diameter relation are discarded [39-43].

2.3. Methods. In order to obtain other characteristics of physical quantities of raindrops, here we first calculate $N\left(D_{i}\right)$ using the following equation [40,42]:

$$
N\left(D_{i}\right)=\sum_{j=1}^{32} \frac{n_{i j}}{A_{i} \cdot \Delta t \cdot V_{j} \cdot \Delta D_{i}},
$$

where $N\left(D_{i}\right)\left(\mathrm{m}^{-3} \cdot \mathrm{mm}^{-1}\right)$ represents the number of raindrops per unit volume per unit diameter interval; $A i\left(\mathrm{~m}^{-2}\right)$ is the sampling area; here, the value is $0.0054 \mathrm{~m}^{-2}$; $n i j$ is the number of raindrops within the size bin $i$ and raindrop terminal velocity bin $j ; V_{j}\left(\mathrm{~m} \cdot \mathrm{s}^{-1}\right)$ is the raindrop fall velocity of the $j$-th bin computed by Atlas et al. [38]; $\Delta t$ (s) is the sample time, here is $60 \mathrm{~s} ; \Delta D_{i}$ is the class spread of the $i$-th bin.

Through DSDs data, the characteristic physical quantities of commonly used raindrops can be derived [41, 42], mainly including rain intensity $R\left(\mathrm{~mm} \cdot \mathrm{h}^{-1}\right)$, liquid water content LWC $\left(\mathrm{g} \cdot \mathrm{m}^{-3}\right)$, and radar reflectivity $Z\left(\mathrm{~mm}^{6} \cdot \mathrm{m}^{-3}\right)$. The calculation formulas are as follows: 


$$
R=\frac{6 \pi}{10000} \sum_{i=1}^{32} \sum_{j=1}^{32} V_{j} \cdot N\left(D_{i}\right) \cdot D_{i}{ }^{3} \cdot \Delta D_{i}, L W C=\frac{\pi \rho_{w}}{6000} \sum_{i=1}^{32} N\left(D_{i}\right) \cdot D_{i}^{3} \cdot \Delta D_{i}, Z=\sum_{i=1}^{32} N\left(D_{i}\right) \cdot D_{i}^{6} \cdot \Delta D_{i}
$$

where $\rho_{w}$ is the density of water, and the value is $1.0 \mathrm{~g} \mathrm{~cm}^{-3}$.

The $n$ th-order moment of the drop size distribution is expressed as follows [44]:

$$
M_{n}=\int_{0}^{\infty} N(D) \cdot D^{n} \cdot d D=N_{0} \frac{\Gamma(n+1+\mu)}{\Lambda^{n+1+\mu}} .
$$

The gamma model can describe the raindrop spectrum very well [45]. At the same time, it cannot be ignored that some researchers have put forward different opinions on this [46, 47]. However, the gamma model has been applied and verified in many studies describing the raindrop spectrum $[7,12,19,25,44,48,49]$, and its form is as follows:

$$
N(D)=N_{0} \cdot D_{\mu} \cdot \exp (-\Lambda \cdot D)
$$

where $N_{0}\left(\mathrm{~mm}^{-1-\mu} \mathrm{m}^{-3}\right), \mu$, and $\Lambda\left(\mathrm{mm}^{-1}\right)$ represent the scale, shape, and slope parameters of the gamma distribution, respectively. The moment method with the third, fourth, and sixth moments to calculate $N 0, \mu$, and $\Lambda$ is used in this study.

$$
\begin{aligned}
N_{0} & =\frac{M_{3} \cdot \Lambda^{\mu+4}}{\Gamma(\mu+4)}, \\
\mu & =\frac{11 \cdot G-8+\sqrt{G \cdot(G+8)}}{2(1-G)}, \\
\Lambda & =(\mu+4) \cdot \frac{M_{3}}{M_{4}}
\end{aligned}
$$

where the calculation formula of $G$ is as follows:

$$
G=\frac{M_{4}^{3}}{M_{3}^{2} M_{6}}
$$

However, the three parameters in the gamma distribution are not completely independent. To solve the nonindependence problem of the parameters of the gamma DSD model, the normalized gamma distribution that can better represent the raindrop spectrum was proposed [50-53]. Its advantages have been confirmed in many studies $[25,36,54,55]$. The normalized gamma distribution formula is as follows:

$$
N(D)=N_{w} \cdot f(\mu) \cdot\left(\frac{D}{D_{m}}\right)^{\mu} \cdot \exp \left[-(4+\mu) \frac{D}{D_{m}}\right],
$$

where $N^{w}\left(\mathrm{~mm}^{-1} \mathrm{~m}^{-3}\right)$ is the normalized intercept parameter and $D^{m}(\mathrm{~mm})$ is the mass-weighted mean diameter. $N^{w}$, $D^{m}$, and $f(\mu)$ are calculated according to formulas (8)-(10), respectively.

$$
\begin{aligned}
N^{w} & =\frac{4^{4}}{\pi \cdot \rho_{w}} \cdot \frac{10^{3} \cdot L W C}{D_{m}^{4}} \\
D_{m} & =\frac{\sum_{i=1}^{32} N\left(D_{i}\right) \cdot D_{i}^{4} \cdot \Delta D_{i}}{\sum_{i=1}^{32} N\left(D_{i}\right) \cdot D_{i}^{3} \cdot \Delta D_{i}} \\
f(\mu) & =\frac{6 \cdot(4+\mu)^{4+\mu}}{4^{4} \cdot \Gamma(4+\mu)}
\end{aligned}
$$

\section{Results}

3.1. Distribution of DSD Parameters. After excluding samples with raindrops less than 10 or rain intensity less than $0.1 \mathrm{~mm} \cdot \mathrm{h}^{-1}$, an effective sample of $17845 \mathrm{~min}$ was obtained. Figure 2 shows the frequency accumulation curve of rainfall intensity recorded. The samples smaller than $0.5 \mathrm{~mm} \cdot \mathrm{h}^{-1}$ accounted for nearly half of the total samples, reaching $46.67 \%$, and the samples smaller than $1 \mathrm{~mm} \cdot \mathrm{h}^{-1}$ accounted for $69.64 \%$ of the total samples. The average rainfall intensity calculated by the $17845 \mathrm{~min}$ data is $0.93 \mathrm{~mm} \cdot \mathrm{h}^{-1}$ (Table 1 ). It can be seen that for the arid area of Xinjiang, water vapor is seriously insufficient, and the rainfall process is mostly weak rainfall [30], which is consistent with the measurement of the rain gauge.

Figure 3 shows the histogram of $D_{m}$ and $\log _{10} N_{w}$ for all samples. The three key statistics including mean, standard deviation (SD), and skewness (SK) are also indicated in Figure 3. The average values of $D_{m}$ and $\log _{10} N_{w}$ are $1.02 \mathrm{~mm}$ and 3.66 , respectively. The $D_{m}$ histogram shows the characteristics of highly positive skewness, and the skewness of $\log _{10} N_{w}$ is -0.37 , indicating that the distribution of $\log _{10} N_{w}$ is more symmetrical. At the same time, the standard deviation of $D_{m}$ and $\log _{10} N_{w}$ reach $0.43 \mathrm{~mm}$ and 0.49 , respectively, which show that $D_{m}$ and $\log _{10} N_{w}$ have high variability. In addition to this, the three key feature statistics of $R, W$, and $Z$ are also shown in Table 1 .

3.2. DSD Characteristics for Different Rainfall Types. In the subsection, the characteristics of raindrop spectra of different rainfall types based on the classification of rainfall as convective precipitation and stratiform precipitation are studied. In the past, many researchers have developed some classification schemes based on disdrometer. For example, Tokay and Short [12] used the $N_{0}-R$ relationship to distinguish between convective precipitation and stratiform precipitation. Testud et al. [53] developed a scheme to distinguish different types of precipitation by $R$. Bringi et al. [28] divided rainfall into convective rainfall and stratiform rainfall based on the standard deviation of $R$ and $R$, this classification method has been applied in many studies, and this research also uses a similar 


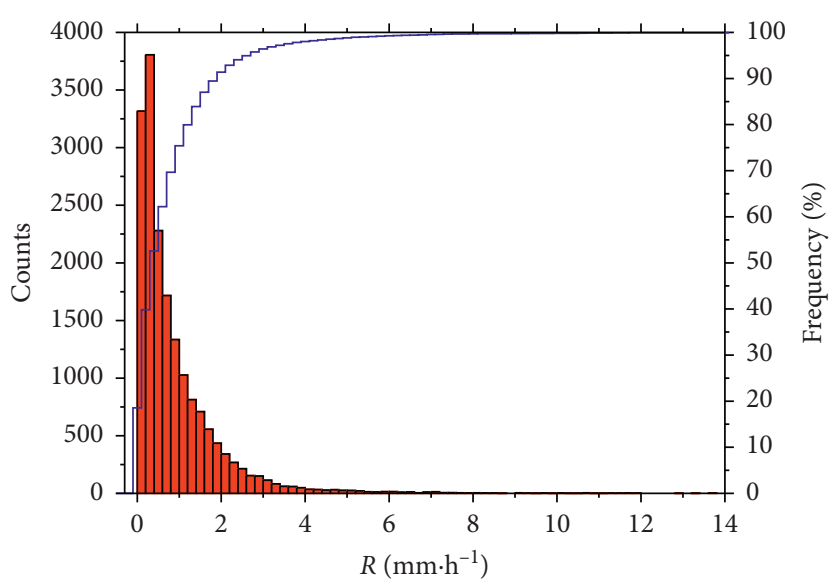

FIGURE 2: Frequency distribution of rain rates calculated from the disdrometer datasets.

TABLE 1: Statistics of DSD parameters for all observations.

\begin{tabular}{|c|c|c|c|c|c|}
\hline Parameters & $D_{m}(\mathrm{~mm})$ & $\log _{10} N_{w}\left(\mathrm{~m}^{-3} \cdot \mathrm{mm}^{-1}\right)$ & $R\left(\mathrm{~mm} \mathrm{~h}^{-1}\right)$ & $W\left(\mathrm{~g} \mathrm{~m}^{-3}\right)$ & $Z(\mathrm{dBZ})$ \\
\hline Mean & 1.02 & 3.66 & 0.93 & 0.10 & 20.29 \\
\hline Standard deviation & 0.43 & 0.49 & 1.23 & 0.41 & 7.50 \\
\hline Skewness & 4.75 & -0.37 & 6.51 & 15.87 & 1.26 \\
\hline
\end{tabular}

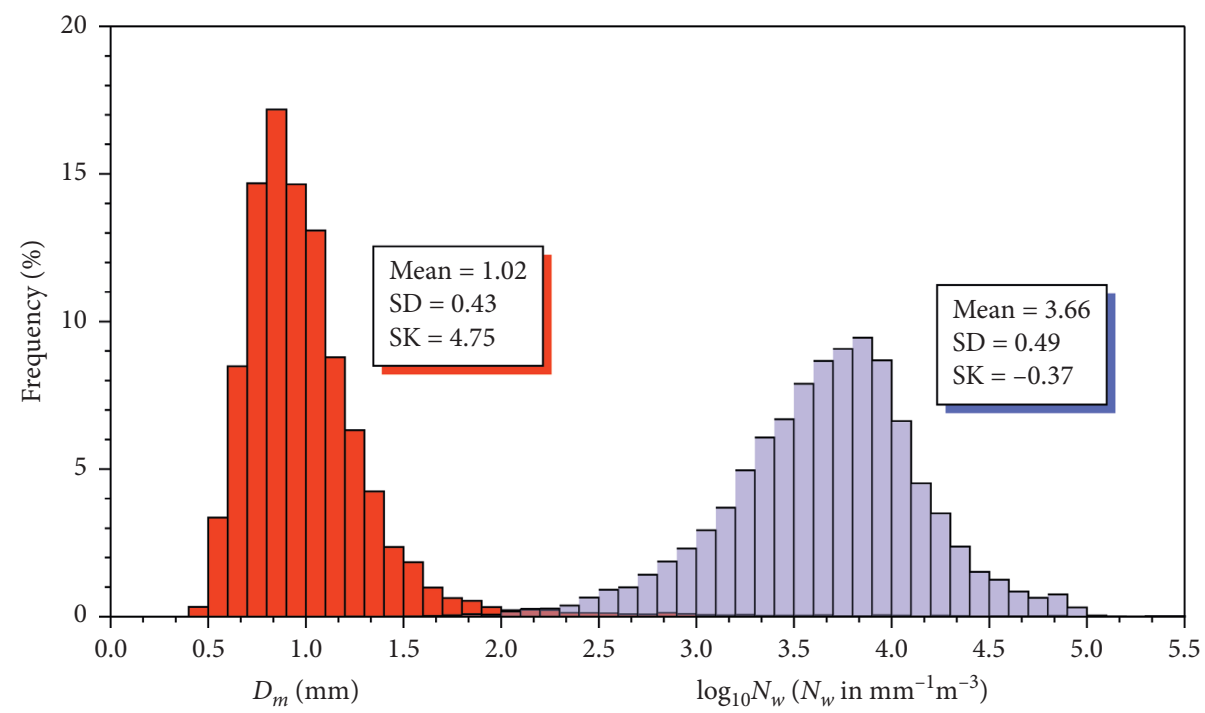

Figure 3: Histograms of $D_{m}$ and $\log _{10} N_{w}$ for all observations. Mean values, standard deviation (SD), and skewness (SK) are also given in each plot.

classification method. Specifically, $R$ of continuous rain for 10 minutes is $0.5 \mathrm{~mm} \cdot \mathrm{h}^{-1} \leq R \leq 0.5 \mathrm{~mm} \mathrm{~h}^{-1}$, and the standard deviation of $R$ is $\leq 1.5 \mathrm{~mm} \cdot \mathrm{h}^{-1}$, which is considered as stratiform precipitation; $R$ of continuous rainfall for 10 minutes is $R \geq$ $5 \mathrm{~mm} \cdot \mathrm{h}^{-1}$, and the standard deviation of $R$ is $>1.5 \mathrm{~mm} \cdot \mathrm{h}^{-1}$, which is considered to be convective precipitation. Through this classification method, 236 convective precipitation samples and 5479 stratiform precipitation samples are obtained. It can be seen that the convective precipitation samples are significantly less than the stratiform precipitation samples, which is mainly due to the fact that the prevalence of minutes of stratiform rain is a quite common feature.
Figure 4 shows the histogram of $D_{m}$ and $\log _{10} N_{w}$ of convective and stratiform rain. $D_{m}$ of both types of rainfall is positive skewness, while the $\log _{10} N_{w}$ of convective rainfall is negative skewness. The average $D_{m}$ of convective rainfall and stratiform rainfall is $1.62 \mathrm{~mm}$ and $1.09 \mathrm{~mm}$, respectively, while the average $\log _{10} N_{w}$ of the two types of rainfall is 3.73 and 3.80, respectively. The standard deviation of $D_{m}$ and $\log _{10} N_{w}$ of convective rainfall is greater than that of stratiform rainfall, indicating that convective rainfall has more extensive changes. In order to more clearly see the difference between the two types of rainfall, Table 2 gives some statistics of convective rainfall, stratiform rainfall, and the overall 


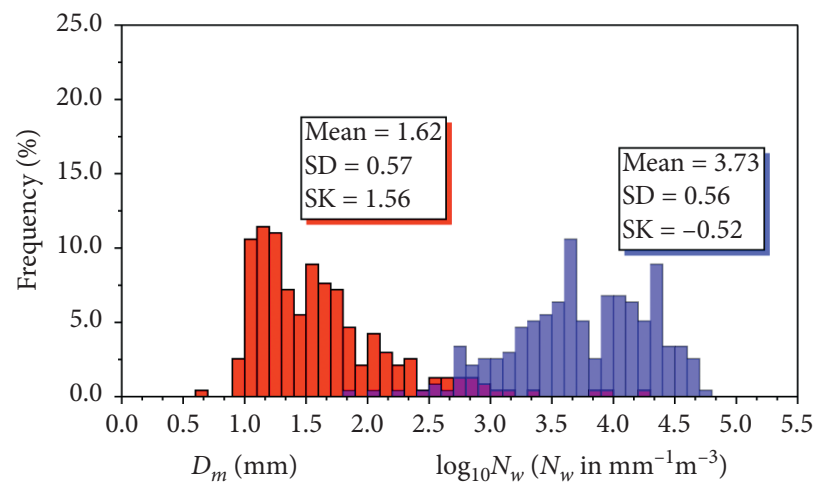

(a)

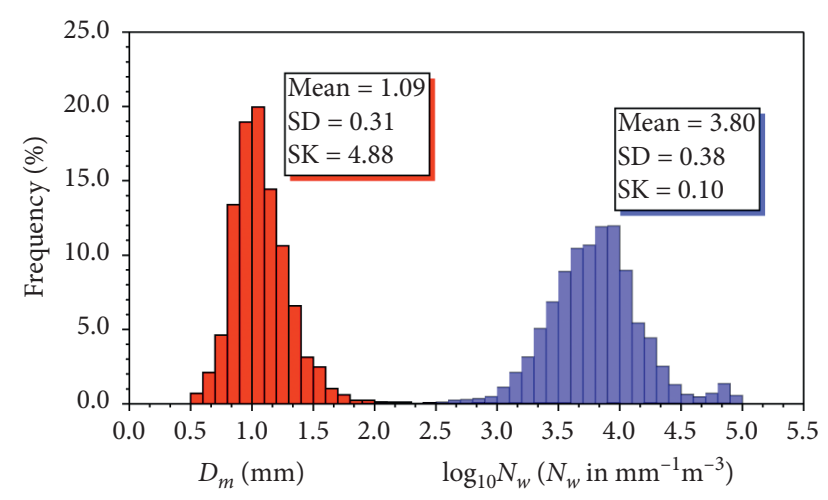

(b)

FIgURE 4: Same as Figure 3 but for convective rainfall (a) and stratiform rainfall (b).

TABLE 2: Statistics of DSD parameters for convective rainfall, stratiform rainfall, and an overall average of the two.

\begin{tabular}{lccccccc}
\hline Parameters & & $D_{m}(\mathrm{~mm})$ & $\log _{10} N_{w}\left(\mathrm{~m}^{-3} \mathrm{~mm}^{-1}\right)$ & $R\left(\mathrm{~mm} \mathrm{~h}^{-1}\right)$ & $W\left(\mathrm{~g} \mathrm{~m} \mathrm{~m}^{-3}\right)$ & $\mu$ & $\Lambda(\mathrm{mm})$ \\
\hline \multirow{2}{*}{ Convective } & Mean & 1.62 & 3.73 & 7.77 & 0.41 & 6.92 & 7.86 \\
& Standard deviation & 0.57 & 0.56 & 3.01 & 0.19 & 4.63 & 5.19 \\
\hline \multirow{2}{*}{ Stratiform } & Mean & 1.09 & 0.38 & 1.51 & 0.11 & 6.56 & 10.98 \\
& Standard deviation & 0.31 & 3.79 & 0.74 & 0.15 & 5.36 & 8.18 \\
\hline \multirow{2}{*}{ Total } & Mean & 1.11 & 0.39 & 1.73 & 0.12 & 6.58 & 10.85 \\
& Standard deviation & 0.34 & & 1.48 & 0.16 & 5.34 \\
\hline
\end{tabular}

rainfall of the two, respectively. It can be seen that the mean $R$ of convective rainfall and stratiform rainfall is $7.77 \mathrm{~mm} \cdot \mathrm{h}^{-1}$ and $1.51 \mathrm{~mm} \cdot \mathrm{h}^{-1}$, respectively. However, due to the fact that there are obviously more stratiform precipitation samples than convective rainfall samples, the average $R$ for overall of the two is only $1.73 \mathrm{~mm} \cdot \mathrm{h}^{-1}$, it is closer to the characteristics of stratiform precipitation, and other statistics have similar trends.

In order to further obtain the relationship between $D_{m}$ and $R$ in different rainfall types, we fitted the $D_{m}-R$ relationship curves of the two types of rainfall as shown in Figure 5. Figure 5 also shows the scatter density plot for $D_{m}-R$. As shown in Figure $5, D_{m}$ and $R$ of convective rainfall are concentrated in $1.0-2.0 \mathrm{~mm}$ and $5.0-6.0 \mathrm{~mm} \cdot \mathrm{h}^{-1}$, respectively, while $D^{m}$ and $R$ of stratiform rain are concentrated in $0.6-1.6 \mathrm{~mm}$ and $1.0-2.0 \mathrm{~mm} \cdot \mathrm{h}^{-1}$, respectively. Both types of rainfall increase as $R$ increases, $D_{m}$ increases (the exponents of the power-law fitting equations are positive), and the distribution of $D_{m}$ becomes narrower. Under higher rainfall intensity $R$, the value of $D_{m}$ tends to be stable, which may be due to the accumulation and rupture of raindrops close to equilibrium [56], and the increase in $R$ in this case may be due to the increase in concentration [57].

Figure 6 shows the scatter plot of $\log _{10} N_{w}$ versus $D_{m}$ for the two rain types, as well as statistical results from different parts of China. The two black rectangles correspond to the maritime and continental convective clusters, and the yellow dashed line is the $\log _{10} N_{w}-D_{m}$ relationship for stratiform rain reported by Bringi et al. [28]. For convective rainfall and stratiform rainfall, there is a difference in the concentration of scattered points. Specifically, the $\log _{10} N_{w}$ and $D_{m}$ of convective rainfall are concentrated in 3.3-4.3 and $1.0-2.0 \mathrm{~mm}$, respectively, and the value of stratiform rainfall is concentrated in $3.1-4.5$ and $0.6-1.6 \mathrm{~mm}$; although there are some overlapping areas, the boundary between the two types of rainfall is clear. For convective rainfall, although there are a few points in the "Continental cluster", most points are neither in the "Continental cluster" nor in the "Maritime cluster" and tend to be close to stratiform rainfall. For stratiform rainfall, most points appear on the left side of the "stratiform line". Comparing the statistical results of DSDs in different regions of China, we got interesting conclusions. In order to reduce the error caused by the measurement of different instruments, we only compared the results measured using the Parsivel disdrometer. The conclusion is that for stratiform rainfall, $D_{m}$ of northern China (Beijing) [14] and northwestern China (Yining) is smaller than that of eastern China (Nanjing) [24], and $D_{m}$ of southern China (Zhuhai) [48] is the largest. At the same time, for stratiform rainfall, although Beijing and Yining have similar $D_{m}$, and $\log _{10} N_{w}$ in Yining is larger than that in Beijing. For convective rainfall, $D_{m}$ in Yining is the smallest, $D_{m}$ in Zhuhai is the largest, and $\log _{10} N_{w}$ in Zhuhai is also the largest. This result shows that the characteristics of DSDs are highly dependent on specific geographic locations and climatic conditions.

Figure 7 shows DSDs of the two rainfall types. There is a big difference in the distribution of DSDs of the two types of rainfall. The peaks of DSDs of convective rainfall and stratiform rainfall are located at $0.7 \mathrm{~mm}$ and $1.2 \mathrm{~mm}$ in diameter, respectively. When the diameter is less than $0.7 \mathrm{~mm}$, DSDs of the two types of rainfall basically coincide, 


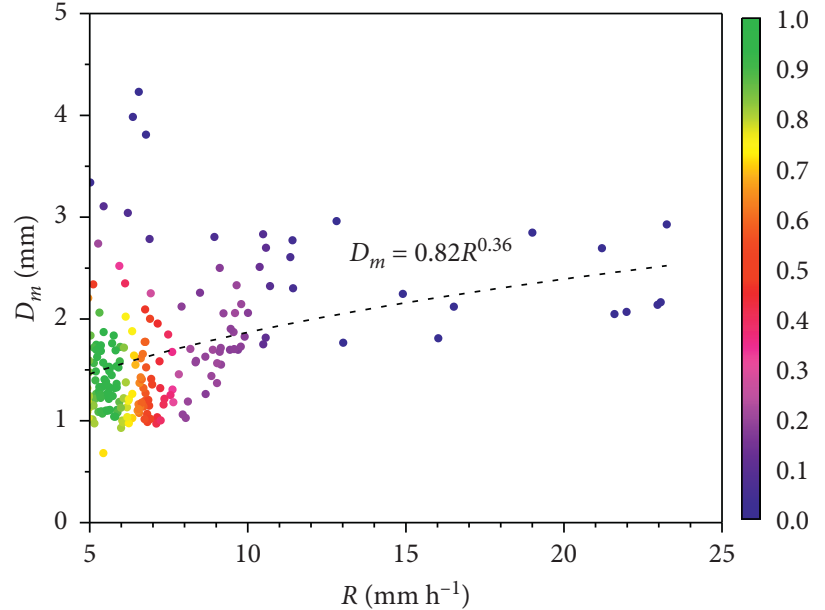

(a)

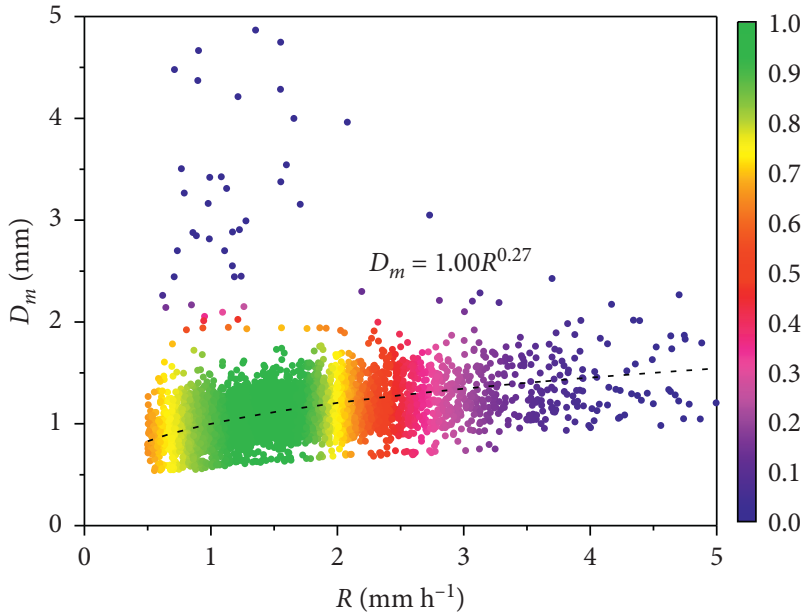

(b)

Figure 5: Scatter density plot for $D_{m}(\mathrm{~mm})$ and $R\left(\mathrm{~mm} \cdot \mathrm{h}^{-1}\right)$ for convective rainfall. (a) And stratiform rainfall (b). The fitted relationships are also provided in each panel adopting a least-squares method, and the color bar represents the relative density of scattered plots.

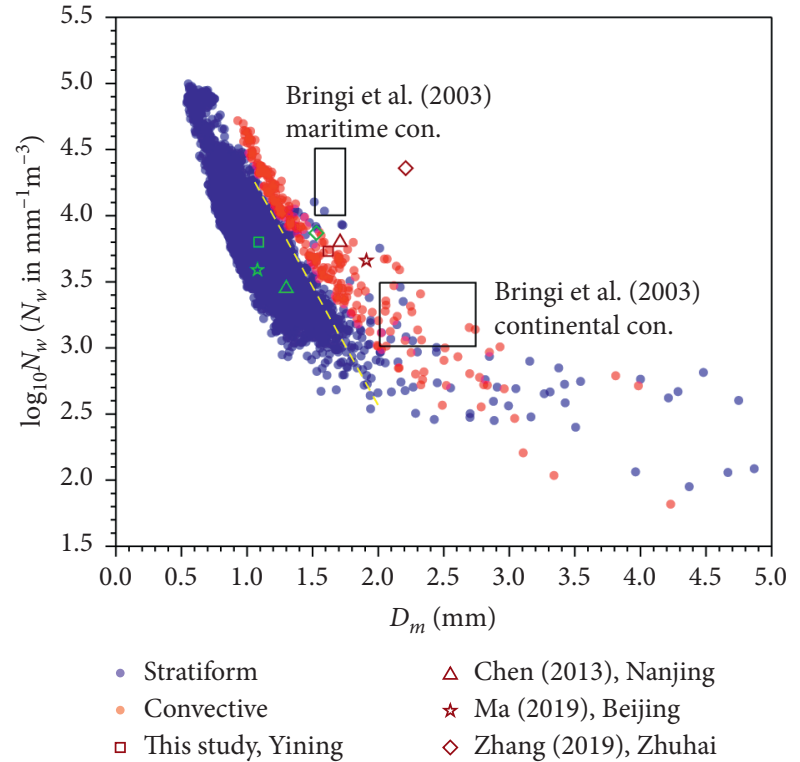

Figure 6: Scatterplot of $\log _{10} N_{w}$ versus $D_{m}$ for convective rains (red filled circles) and stratiform rains (blue filled circles). The two black rectangles correspond to the maritime and continental convective clusters, and the yellow dashed line is the $\log _{10} N_{w}-D_{m}$ relationship for stratiform rain reported by Bringi et al. [28]. The squares represent the averaged values in this study. The triangles, circles, stars, and diamonds represent the averaged values obtained in previous studies by Chen et al. [24], Ma et al. [14], and Zhang et al. [48] for different parts of China. The colors of these symbols represent different rains: green for stratiform rains and brown for convective rains.

but when the diameter is greater than $0.7 \mathrm{~mm}$, the DSD of convective rainfall is located above the stratiform rain. It can be seen that there are larger raindrops in convective rainfall than stratiform rainfall, and these large raindrops contribute more to rainfall intensity.

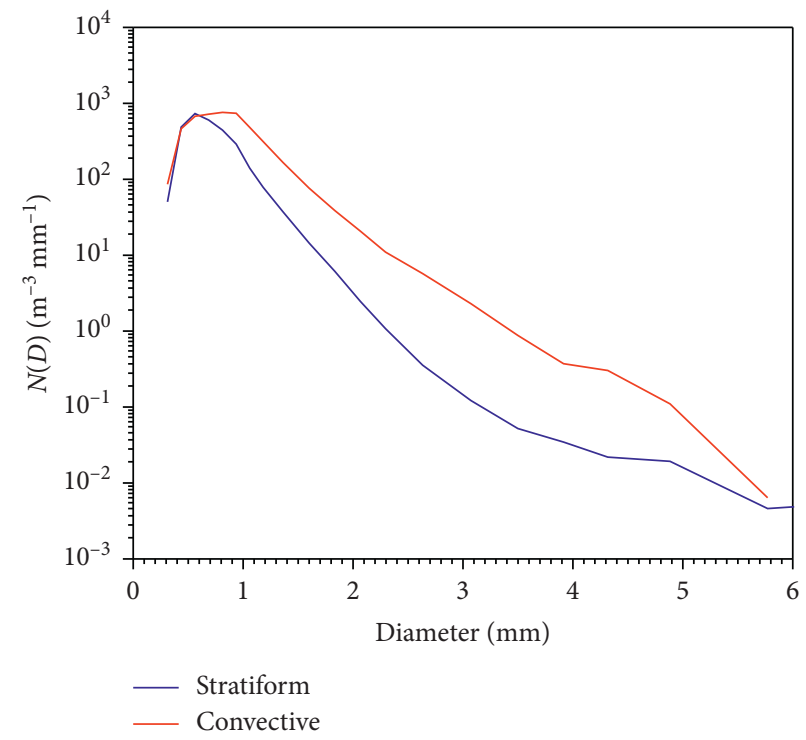

Figure 7: Average size spectra for convective (red line) and stratiform (blue line) rain.

3.3. DSD Characteristics in Different Rainfall Rate Classes. Previous studies have shown that DSDs of different rainfall intensities show different properties $[12,58]$, and Chen et al. [7] divided DSDs measured on the Qinghai-Tibet Plateau into 5 classes according to $R$. Seela et al. [26] compared DSDs of Palau and Taiwan and divided DSDs into 12 classes according to $R$. Ma et al. [14] divided the rainfall into 8 classes when studying the nature of DSDs in Beijing. In order to further understand the nature of DSDs under different rainfall intensities in Xinjiang, drawing on the classification criteria previously studied, and combining the fact that Xinjiang rainfall is mainly weak rainfall [30], DSDs are divided into 6 classes according to $R$ : $\mathrm{C} 1$, $0.1 \leq R<0.5 \mathrm{~mm} \cdot \mathrm{h}^{-1} ; \quad \mathrm{C} 2, \quad 0.5 \leq \quad R<1 \mathrm{~mm} \cdot \mathrm{h}^{-1} ; \quad \mathrm{C} 3$, 
TABLE 3: Number and DSD retrieved rain rate statistics of each rain rate class.

\begin{tabular}{|c|c|c|c|c|c|}
\hline Rain rate class & Rain rate threshold $\left(\mathrm{mm} \mathrm{h}^{-1}\right)$ & No. of samples & Mean $\left(\mathrm{mm} \mathrm{h}^{-1}\right)$ & Standard deviation $\left(\mathrm{mm} \mathrm{h}^{-1}\right)$ & Skewness $\left(\mathrm{mm} \mathrm{h}^{-1}\right)$ \\
\hline $\mathrm{C} 1$ & $0.1 \leq \mathrm{R}<0.5$ & 8328 & 0.26 & 0.11 & 0.46 \\
\hline $\mathrm{C} 2$ & $0.5 \leq \mathrm{R}<1$ & 4100 & 0.72 & 0.14 & 0.23 \\
\hline $\mathrm{C} 3$ & $1 \leq \mathrm{R}<2$ & 3533 & 1.42 & 0.28 & 0.35 \\
\hline $\mathrm{C} 4$ & $2 \leq \mathrm{R}<5$ & 1648 & 2.82 & 0.73 & 1.10 \\
\hline C5 & $5 \leq \mathrm{R}<10$ & 198 & 6.41 & 1.18 & 0.95 \\
\hline C6 & $\mathrm{R} \geq 10$ & 38 & 14.87 & 5.73 & 1.27 \\
\hline
\end{tabular}

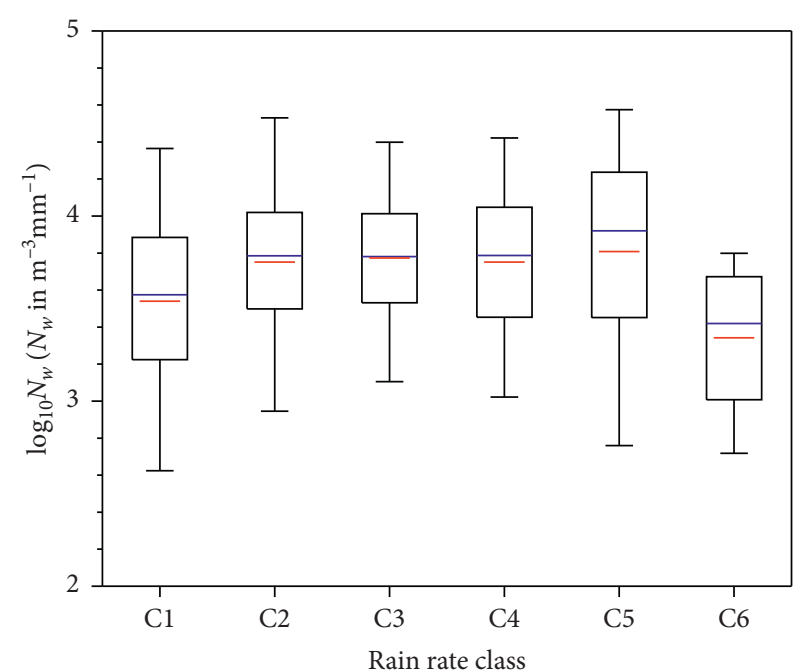

(a)

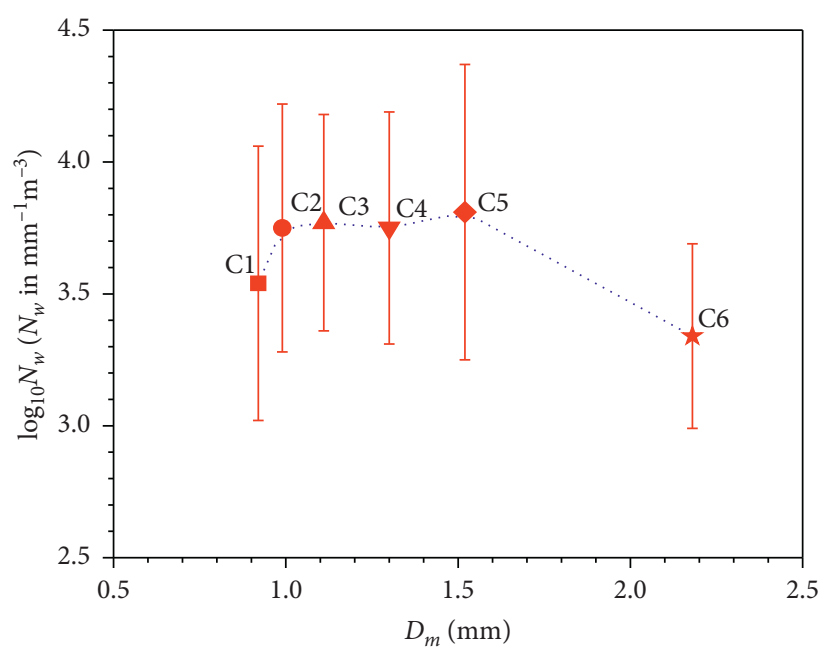

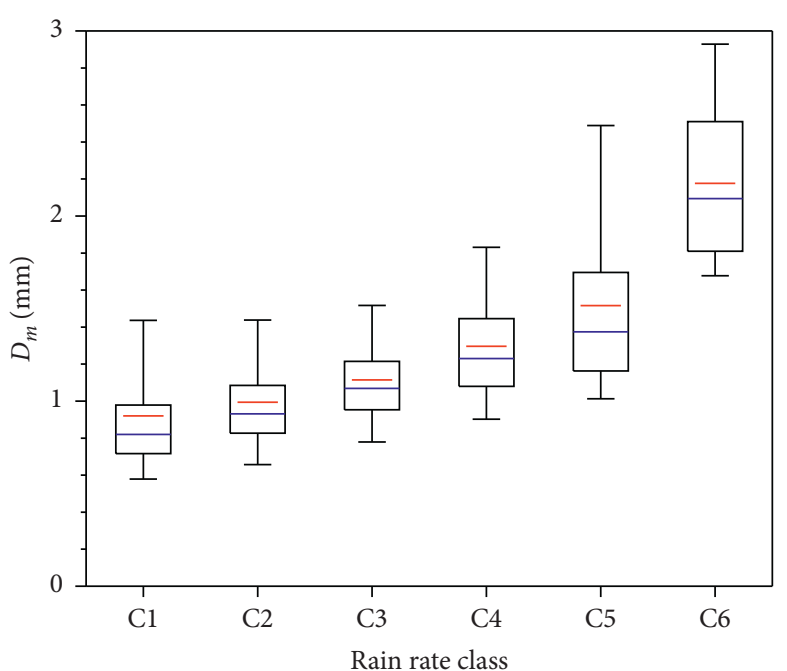

(b)

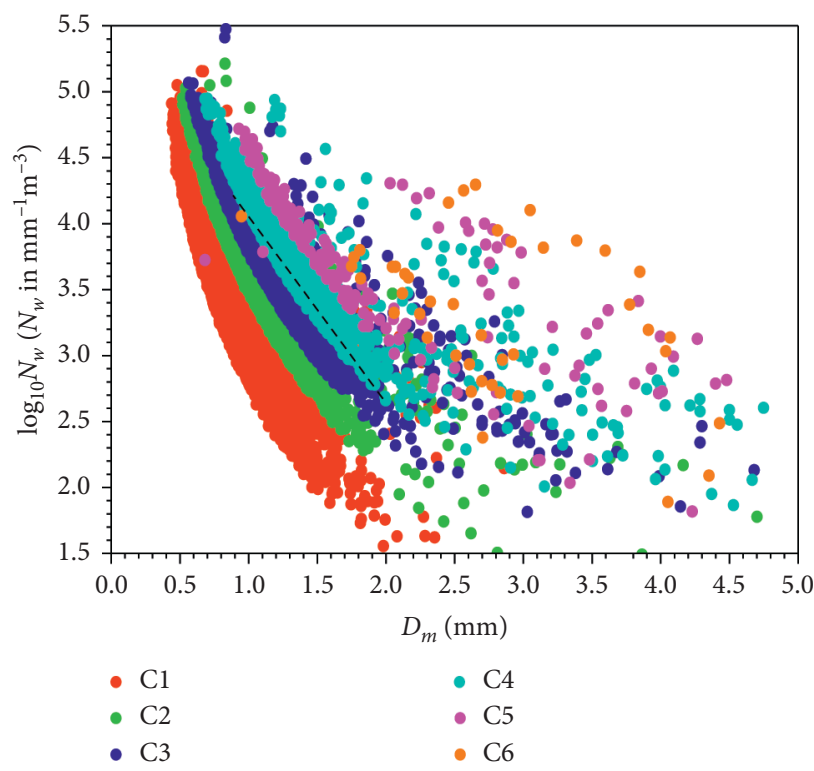

(d)

Figure 8: Variation of the normalized intercept parameter (a) and the mass-weighted mean diameter (b) for different rain rate classes. The blue central line of the box indicates the median, the red central line in the box indicates the mean values, and the bottom and top lines of the box indicate the $25^{\text {th }}$ and $75^{\text {th }}$ percentiles, respectively. The bottom and top lines of the vertical lines out of the box indicate the $5^{\text {th }}$ and $95^{\text {th }}$ percentiles, respectively. Variation of mean normalized intercept parameter (along with \pm 1 standard deviation) with a mass-weighted mean diameter in different rain classes (c). Scatterplot of $\log _{10} N_{w}$ versus $D_{m}$ for different rain rate classes (d). The black dashed line is the $\log _{10} N_{w}-D_{m}$ relationship for stratiform rain reported by Bringi et al. [28]. 
$1 \leq R<2 \mathrm{~mm} \cdot \mathrm{h}^{-1} ; \mathrm{C} 4,2 \leq R<5 \mathrm{~mm} \cdot \mathrm{h}^{-1} ; \mathrm{C} 5,5 \leq R<10$ $\mathrm{mm} \mathrm{h}^{-1}$; C6, $R \geq 10 \mathrm{~mm} \mathrm{~h}^{-1}$. The statistics of sample numbers and $R$ for each rain rate class are summarized in Table 3.

Figures 8(a) and 8(b) show the changes in $\log _{10} N_{w}$ and $D_{m}$ of the six rainfall rate classes in the form of box-andwhisker plots, respectively. $D_{m}$ increases with the increase of $R$, while $\log _{10} N_{w}$ shows a trend of first increasing and then decreasing. In order to see more clearly the changing trend of the two with the increase of $R$, Figure 8(c) shows the variation of mean $\log _{10} N_{w}$ (along with \pm 1 standard deviation) with $D_{m}$ in different rain classes. It can be seen that the average value of $D_{m}$ has a wider range of variation than the average value of $\log _{10} N_{w}$, and the variation is more significant under heavy rainfall classes. At the same time, Table 4 shows the specific average values and standard deviations of $D_{m}$ and $\log _{10} N_{w}$ for the six rainfall rate classes. The average value of $D_{m}$ varies from 0.92 to $2.18 \mathrm{~mm}$, and the average value of $\log 10 \mathrm{~N}^{w}$ varies from 3.34 to 3.81 . In addition, a scatterplot of $\log _{10} N_{w}$ versus $D_{m}$ for different rain rate classes is shown in Figure 8(d), and the black dashed line is the $\log _{10} N_{w}-D_{m}$ relationship for stratiform rain reported by Bringi et al. [28]. It can be seen that with the increase of $R$, $D_{m}$ shows an increasing trend, and the dispersion of scattered points strengthens. The scattered points of C3 and C4 are closer to the black dashed line, and the corresponding rainfall rate is $1-5 \mathrm{~mm}$.

To facilitate the comparison of the average DSDs between different rainfall rate classes, the average DSDs for different rain rate classes are superimposed on the same graph (Figure 9). It can be clearly seen that as $R$ increases, the spectrum width of the DSDs increases, and the diameter corresponding to the peak of DSDs increases. In the range of smaller diameters (less than $0.6 \mathrm{~mm}$ ), the corresponding concentrations of different rainfall rate classes are similar, and when the diameter is greater than $0.6 \mathrm{~mm}$, the corresponding concentrations of high rainfall rate classes show an increasing trend. It can be seen that there are particles with smaller diameters in each rainfall rate class, and the main factor that increases the rainfall rate is to have more particles with larger diameters.

3.4. $Z$-R Relationship. The power-law relationship $Z=A \cdot R^{b}$ obtained by $Z$ and $R$ is the most widely used algorithm in QPEs of single-polarization radar (including the radar currently used in Yining). However, many researchers have pointed out that the coefficient $\mathrm{A}$ and the index $b$ in the relationship have strong variability. The continental stratiform rain relation reported by Marshall and Palmer [59] is $Z=200.00 R^{1.60}$, and in the United States, the default $Z-R$ relationship in the operational Weather Surveillance Radar1988 Doppler (WSR-88D) systems is $Z=300.00 R^{1.40}$ [60]. In the past, some researchers have carried out localized $Z-R$ relationship studies in different regions of China using the Parsivel disdrometer, which has a certain significance for improving local precipitation quantitative estimation capabilities $[14,24,48,61,62]$. In this study, we used the least square method to derive the $Z-R$ relationship of different rainfall types in the Yining area, with the purpose of providing
TABLE 4: Mean and standard deviation values of $D_{m}$ and $\log _{10} N_{w}$ in different rain rate classes.

\begin{tabular}{ccccc}
\hline & & $D_{m}(\mathrm{~mm})$ & \multicolumn{2}{c}{$\log _{10} N_{w}\left(\mathrm{~m}^{-3} \cdot \mathrm{mm}^{-1}\right)$} \\
& Mean & Standard deviation & Mean & Standard deviation \\
\hline C1 & 0.92 & 0.47 & 3.54 & 0.52 \\
C2 & 0.99 & 0.34 & 3.75 & 0.47 \\
C3 & 1.11 & 0.33 & 3.77 & 0.41 \\
C4 & 1.30 & 0.39 & 3.75 & 0.44 \\
C5 & 1.52 & 0.53 & 3.81 & 0.56 \\
C6 & 2.18 & 0.42 & 3.34 & 0.35 \\
\hline
\end{tabular}

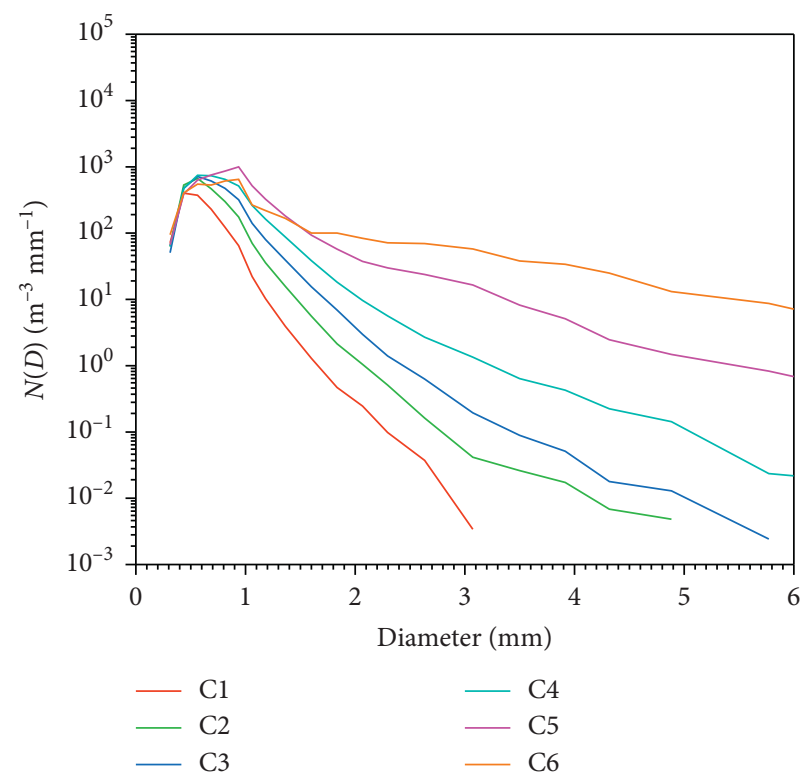

Figure 9: Average size spectra for different rain rate classes.

a reference for quantitative estimation of precipitation in this area.

Figure 10 is a scatter plot of the $Z-R$ relationship between convective precipitation and stratiform precipitation and the corresponding fitting curves. For comparison, the default $Z-R$ relationship in WSR-88D [60] and the continental stratiform rain relation reported by Marshall and Palmer [59] are also indicated in Figure 10. For stratiform rain, most of the continental stratiform rain relation reported by Marshall and Palmer [59] will overestimate the rainfall fitting from this study, and this overestimation is more obvious under high reflectivity conditions. The default $Z-R$ relationship in WSR-88D will underestimate stratiform precipitation with lower reflectance values and overestimate stratiform precipitation with higher reflectance values. As for convective rainfall, the overall trend is overestimated. In addition, in order to compare with different regions in China, we also plot the $Z-R$ relationship of convective precipitation and stratiform precipitation in different regions of China, including Nagqu in western China [63], Yangjiang in southern China [63], Nanjing in eastern China [62], and Beijing in northern China [64]. 


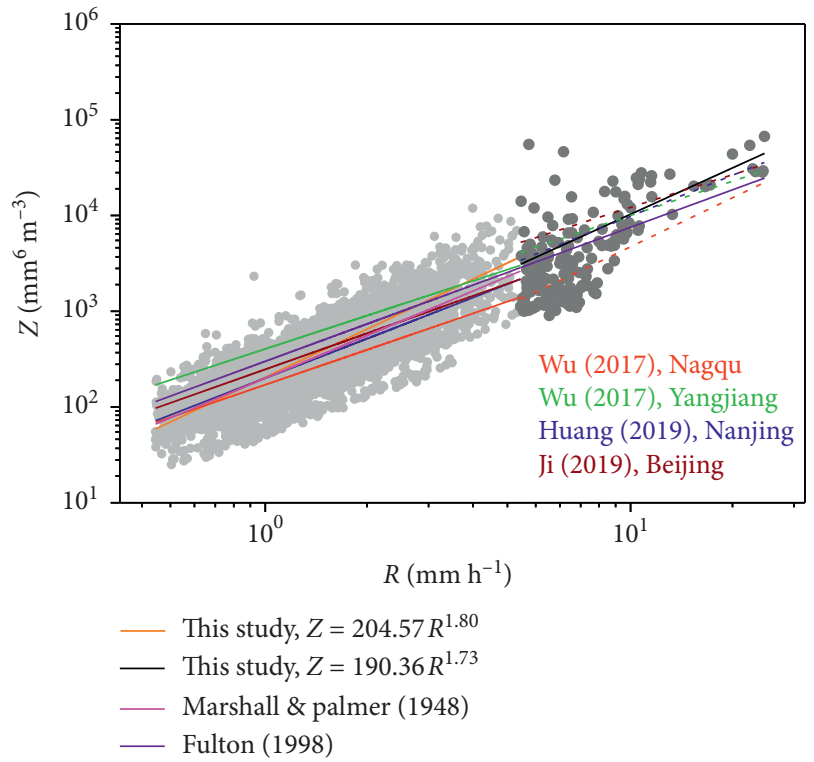

FIgURE 10: Scatterplots of $Z-R$ values for convective rain (dark gray dots) and stratiform rain (light gray dots). The fitted powerlaw relationships of convective and stratiform rain in the form of $Z=A \cdot R^{b}$ are shown in orange and black solid lines, respectively. The magenta solid line denotes the continental stratiform rain relation reported by Marshall and Palmer [59]. The purple solid line denotes the default NEXRAD relation reported by Fulton et al. [60]. The red, green, blue, and wine red lines represent the $Z-R$ relations obtained in previous studies by Wu et al. [63], Wu et al. [63], Huang et al. [62], and Ji et al. [64] for different parts of China. The different line types represent different rains: solid lines for stratiform rains, and dashed lines for convective rains.

Obviously, the differences in $Z-R$ relationship in various regions are significant, which also shows that localized research is very necessary.

3.5. $\mu-\Lambda$ Relationship. The fact that the $\mu-\Lambda$ relationship can better describe the variability of DSDs during natural rainfall has been widely proven $[21,24,49,65]$. A large number of previous studies have shown that this relationship is different under different climatic conditions [66-69]. Therefore, it is necessary to study the Yining area of Xinjiang located in a typical arid area. Figure 11 shows scatterplots of $\mu-\Lambda$ values in the Yining area. The gray solid circles are points from all the data, the dispersion of these scattered points is very large, so in order to reduce the dispersion, refer to Chen et al. [7] processing method, that is, DSD data are filtered by allowing only those with total drop counts $>300$, these data points are represented by black circles, and the corresponding fitted quadratic polynomials are as follows:

$$
\mu=-0.0020 \Lambda^{2}+0.6609 \Lambda-0.4299 \text {. }
$$

Comparing the research results of Chen et al. [7], it can be seen that in the smaller value part, the two fitting curves overlap better, but in the larger value part, the divergence of the two curves becomes obvious. This also further shows that

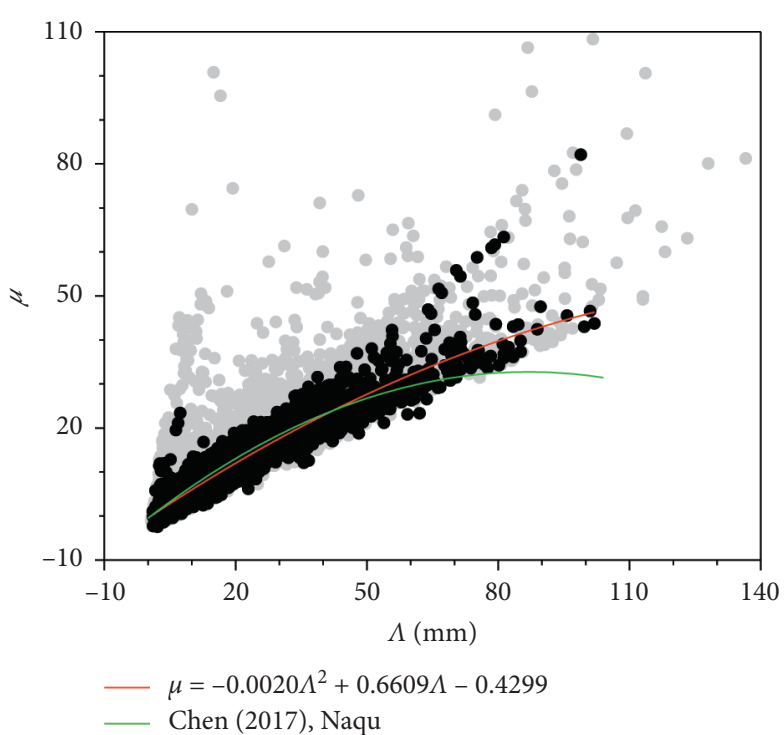

Figure 11: Scatterplots of $\mu-\Lambda$ values. The gray and black solid circles are points from all the data and the filtered data with drop counts $>300$, respectively. The red line and the equation shown in the figure represent a least-squares fit to the filtered data. The green line represents the $\mu-\Lambda$ relation in previous studies by Chen et al. [7].

under different climate conditions, the variability of precipitation microphysics is obvious.

\section{Discussion}

The nature of DSD changes accordingly with the differences in climate regions, topography, and rainfall types [1-15]. In the past, a large number of studies have been carried out on DSDs of many continental and ocean areas, and the research conclusions are of great help in improving the understanding of the microphysical process of rainfall [16-28]. However, past studies have mainly focused on monsoon regions with abundant rainfall and have paid less attention to arid regions. For example, for China, past research mainly focused on the southern, eastern, and northern regions of China, which are humid regions controlled by the monsoon system $[2,13,14,22-24]$, while there is less research on arid regions in China. At present, for the arid regions of China, researchers pay more attention to the raindrop spectrum of the Qinghai-Tibet Plateau [7, 63] and lack research on Xinjiang. Therefore, the conclusions of this study are conducive to understanding the microphysical properties of rainfall in Xinjiang. Through comparison, some differences between Xinjiang and humid regions of China have been found. For example, regardless of stratiform rainfall or convective rainfall, $D^{m}$ of Xinjiang is smaller than that of humid areas of China, which shows that the particles in Xinjiang are smaller during rainfall. At the same time, the $Z-R$ relationship we deduced is also different from that of humid areas of China, which has reference value for improving QPE in Xinjiang. This study has obtained the overall DSD properties of the annual rainfall. However, DSDs of 
different seasons and different months are also different, which will be further carried out in future work.

\section{Conclusions}

In this study, we used the raindrop spectrum data of Yining of Xinjiang during the rainy season (April to October) from July 2018 to August 2020 to study the nature of DSD in Xinjiang in arid areas. The main findings are as follows:

(1) For all rain samples, rainfall appears in the form of weaker intensity, and nearly $70 \%$ of the rainfall rate is less than $1 \mathrm{~mm} \mathrm{~h}^{-1}$, and the DSD parameter $\left(D^{m}\right)$ and bulk variables $(R, W$ and $Z$ ) have a positive skewness, indicating a low frequency of high values and a high frequency of low values in Yining. The larger standard deviations of these parameters indicate that the rainfall variability is stronger.

(2) The statistically obtained convective rainfall samples are significantly less than the stratiform rainfall samples. The mass-weighted average diameter $D^{m}$ and $R$ of convective rainfall are concentrated in $1.0-2.0 \mathrm{~mm}$ and $5.0-6.0 \mathrm{~mm} \cdot \mathrm{h}^{-1}$, respectively, while $D^{m}$ and $R$ of stratiform rain are concentrated in $0.6-1.6 \mathrm{~mm}$ and $1.0-2.0 \mathrm{~mm} \cdot \mathrm{h}^{-1}$, respectively. As $R$ increases, $D^{m}$ increases, and the distribution of $D^{m}$ becomes narrower. Convective rainfall in the Yining area is neither in the "Continental cluster" nor in the "Maritime cluster" and tends to approach stratiform rain. For stratiform rain, most points appear on the left side of the "stratiform line". The peaks of the raindrop spectra of convective rain and stratus rain are located at $0.7 \mathrm{~mm}$ and $1.2 \mathrm{~mm}$ in diameter, respectively. When the diameter is less than $0.7 \mathrm{~mm}$, DSDs of the two rainfalls basically coincide, but when the diameter is greater than $0.7 \mathrm{~mm}$, DSDs of convective rainfall are located above that of the stratiform rain.

(3) According to different rainfall intensities, the raindrop spectrum is divided into 6 classes. It is found that $D^{m}$ increases with the increase of $R$, and the standardized intercept parameterlog $10 \mathrm{~N}^{w}$ shows a trend of first increasing and then decreasing. As $R$ increases, the spectrum width of DSDs increases, and the diameter corresponding to the peak of DSDs increases. In the range of smaller diameters (less than $0.6 \mathrm{~mm}$ ), the corresponding concentrations of different rainfall rate classes are similar, and when the diameter is greater than $0.6 \mathrm{~mm}$, the corresponding concentrations of high rainfall rate classes show an increasing trend.

(4) We deduced the $Z-R$ relationship in the Yining area and found that the default $Z-R$ relationship in WSR$88 \mathrm{D}$ will underestimate stratiform precipitation with lower reflectance values and overestimate stratiform precipitation with higher reflectance values. As for convective rainfall, the overall trend is overestimated. We also deduced the $\mu-\Lambda$ relationship, compared with Chen et al. (2017), the two fitted curves agree better in the smaller value part, and when the value is larger, the two curves are more different.

\section{Data Availability}

Data used in this paper can be obtained from Yong Zeng (15099610397@163.com) upon request.

\section{Conflicts of Interest}

The authors declare no conflicts of interest.

\section{Acknowledgments}

This research was funded by the National Key Research and Development Program of China (2018YFC1507102 and 2018YFC1507104) and Basic Business Expenses (IDM2019001).

\section{References}

[1] D. Rosenfeld and C. W. Ulbrich, "Cloud microphysical properties, processes, and rainfall estimation opportunities," Meteorological Monographs, vol. 30, no. 52, p. 237, 2003.

[2] B. Chen, W. Hu, and J. Pu, "Characteristics of the raindrop size distribution for freezing precipitation observed in southern China," Journal of Geophysical Research, vol. 116, no. D6, Article ID D06201, 2011.

[3] S. Niu, X. Jia, J. Sang, X. Liu, C. Lu, and Y. Liu, "Distributions of raindrop sizes and fall velocities in a semiarid plateau climate: convective versus stratiform rains," Journal of Applied Meteorology and Climatology, vol. 49, no. 4, pp. 632-645, 2010.

[4] K. Chakravarty and P. E. Raj, "Raindrop size distributions and their association with characteristics of clouds and precipitation during monsoon and post-monsoon periods over a tropical Indian station," Atmospheric Research, vol. 124, pp. 181-189, 2013.

[5] S.-A. Jung, D.-I. Lee, B. J.-D. Jou, and H. Uyeda, "Microphysical properties of maritime squall line observed on June 2, 2008 in Taiwan," Journal of the Meteorological Society of Japan, vol. 90, no. 5, pp. 833-850, 2012.

[6] F. S. Marzano, D. Cimini, and M. Montopoli, "Investigating precipitation microphysics using ground-based microwave remote sensors and disdrometer data," Atmospheric Research, vol. 97, no. 4, pp. 583-600, 2010.

[7] B. J. Chen, Z. Q. Hu, L. P. Liu, and G. F. Zhang, "Raindrop size distribution measurements at $4,500 \mathrm{~m}$ on the Tibetan plateau during TIPEX-III," Journal of Geophysical Research: Atmospheres, vol. 122, no. 20, pp. 11092-11106, 2017.

[8] B. J. Chen and H. Xiao, "Silver iodide seeding impact on the microphysics and dynamics of convective clouds in the high plains," Atmospheric Research, vol. 96, no. 1-2, pp. 186-207, 2010.

[9] R. Harikumar, V. Sasi Kumar, S. Sampath, and P. V. S. S. K. Vinayak, "Comparison of drop size distribution between stations in Eastern and Western coast of India," Journal of Indian Geophysical Union, vol. 11, no. 2, pp. 111116, 2007.

[10] M. Maki, T. D. Keenan, Y. Sasaki, and K. Nakamura, "Characteristics of the raindrop size distribution in tropical continental squall lines observed in Darwin, Australia," 
Journal of Applied Meteorology, vol. 40, no. 8, pp. 1393-1412, 2001.

[11] S. Moumouni, M. Gosset, and E. Houngninou, "Main features of rain drop size distributions observed in Benin, West Africa, with optical disdrometers," Geophysical Research Letters, vol. 35, no. 23, Article ID L23807, 2008.

[12] A. Tokay and D. A. Short, "Evidence from tropical raindrop spectra of the origin of rain from stratiform versus convective clouds," Journal of Applied Meteorology, vol. 35, no. 3, pp. 355-371, 1996.

[13] L. Wen, K. Zhao, M. Wang, and G. Zhang, "Seasonal variations of observed raindrop size distribution in east China," Advances in Atmospheric Sciences, vol. 36, no. 4, pp. 346-362, 2019.

[14] Y. Ma, G. Ni, C. V. Chandra, F. Tian, and H. Chen, "Statistical characteristics of raindrop size distribution during rainy seasons in the Beijing urban area and implications for radar rainfall estimation," Hydrology and Earth System Sciences, vol. 23, no. 10, pp. 4153-4170, 2019.

[15] M.-T. Lee, P.-L. Lin, W.-Y. Chang, B. K. Seela, and J. Janapati, "Microphysical characteristics and types of precipitation for different seasons over north Taiwan," Journal of the Meteorological Society of Japan, vol. 97, no. 4, pp. 841-865, 2019.

[16] G. Penide, V. V. Kumar, A. Protat, and P. T. May, "Statistics of drop size distribution parameters and rain rates for stratiform and convective precipitation during the north Australian wet season," Monthly Weather Review, vol. 141, no. 9, pp. 3222-3237, 2013.

[17] B. Radhakrishna, T. N. Rao, D. N. Rao, N. P. Rao, K. Nakamura, and A. K. Sharma, "Spatial and seasonal variability of raindrop size distributions in southeast India," Journal of Geophysical Research: Atmospheres, vol. 114, no. 4, Article ID D04203, 2009.

[18] C. H. You and D. I. Lee, "Decadal variation in raindrop size distributions in Busan, Korea," Advances in Meteorology, vol. 2015, Article ID 329327, 8 pages, 2015.

[19] B. K. Seela, J. Janapati, P.-L. Lin, P. K. Wang, and M.-T. Lee, "Raindrop size distribution characteristics of summer and winter season rainfall over north Taiwan," Journal of Geophysical Research: Atmospheres, vol. 123, no. 20, pp. 1160211624, 2018.

[20] L. S. Kumar, Y. H. Lee, and J. T. Ong, "Two-parameter gamma drop size distribution models for Singapore," IEEE Transactions on Geoscience and Remote Sensing, vol. 49, no. 9, pp. 3371-3380, 2011.

[21] Q. Cao, G. Zhang, E. Brandes, T. Schuur, A. Ryzhkov, and $\mathrm{K}$. Ikeda, "Analysis of video disdrometer and polarimetric radar data to characterize rain microphysics in Oklahoma," Journal of Applied Meteorology and Climatology, vol. 47, no. 8, pp. 2238-2255, 2008.

[22] L. Wen, K. Zhao, G. Zhang et al., "Statistical characteristics of raindrop size distributions observed in east China during the Asian summer monsoon season using 2-D video disdrometer and micro rain radar data," Journal of Geophysical Research: Atmospheres, vol. 121, no. 5, pp. 2265-2282, 2016.

[23] B. Chen, J. Wang, and D. Gong, "Raindrop size distribution in a midlatitude continental squall line measured by Thies optical disdrometers over east China," Journal of Applied Meteorology and Climatology, vol. 55, no. 3, pp. 621-634, 2016.

[24] B. Chen, J. Yang, and J. Pu, "Statistical characteristics of raindrop size distribution in the Meiyu season observed in eastern China," Journal of the Meteorological Society of Japan, vol. 91, no. 2, pp. 215-227, 2013.
[25] Z. Wu, Y. Zhang, L. Zhang et al., "Characteristics of summer season raindrop size distribution in three typical regions of western pacific," Journal of Geophysical Research: Atmospheres, vol. 124, no. 7, pp. 4054-4073, 2019.

[26] B. K. Seela, J. Janapati, P.-L. Lin, K. K. Reddy, R. Shirooka, and P. K. Wang, "A comparison study of summer season raindrop size distribution between Palau and Taiwan, two islands in western Pacific," Journal of Geophysical Research: Atmospheres, vol. 122, no. 21, pp. 11787-11805, 2017.

[27] C. W. Ulbrich and D. Atlas, "Microphysics of raindrop size spectra: tropical continental and maritime storms," Journal of Applied Meteorology and Climatology, vol. 46, no. 11, pp. 1777-1791, 2007.

[28] V. N. Bringi, V. Chandrasekar, J. Hubbert, E. Gorgucci, W. L. Randeu, and M. Schoenhuber, "Raindrop size distribution in different climatic regimes from disdrometer and dual-polarized radar analysis," Journal of the Atmospheric Sciences, vol. 60, no. 2, pp. 354-365, 2003.

[29] F. Chen, Z. Yu, M. Yang et al., "Holocene moisture evolution in arid central Asia and its out-of-phase relationship with Asian monsoon history," Quaternary Science Reviews, vol. 27, no. 3-4, pp. 351-364, 2008.

[30] J. B. Zhang and Z. F. Deng, A Generality of Rainfall in Xinjiang, Meteorological Press, Beijing, China, 1987, in Chinese.

[31] L. M. Yang, X. Li, and G. X. Zhang, "Some advances and problems in the study of heavy rain in Xinjiang," Climatic and Environmental Research, vol. 16, no. 2, pp. 188-198, 2011, in Chinese.

[32] Y. Zeng and L. M. Yang, "Mesoscale analysis on the "6.16" heavy precipitation process in the West of Xinjiang," Torrential Rain and Disasters, vol. 39, no. 1, pp. 41-51, 2020, in Chinese.

[33] Y. Zeng, Y. S. Zhou, and L. M. Yang, “A preliminary analysis of the formation mechanism for a heavy rainstorm in western Xinjiang by numerical simulation," Chinese Journal of Atmospheric Sciences, vol. 43, no. 2, pp. 372-388, 2019, in Chinese.

[34] Y. Zeng and L. Yang, "Triggering mechanism of an extreme rainstorm process near the tianshan Mountains in Xinjiang, an arid region in China, based on a numerical simulation," Advances in Meteorology, vol. 2020, Article ID 8828060, 12 pages, 2020.

[35] L. M. Yang, Y. H. Zhang, and H. Tang, "Analyses on water vapor characteristics in three heavy rainstorm processes of Xinjiang in July 2007," Plateau Meteorology, vol. 31, no. 4, pp. 963-973, 2012, in Chinese.

[36] Y. Zeng, L. Yang, Z. Zhang et al., "Characteristics of clouds and raindrop size distribution in Xinjiang, using cloud radar datasets and a disdrometer," Atmosphere, vol. 11, no. 12, p. 1382, 2020.

[37] M. Loffler-Mang and J. Joss, "An optical disdrometer for measuring size and velocity of hydrometeors," Journal of Atmospheric and Oceanic Technology, vol. 17, no. 2, pp. 130-139, 2000.

[38] D. Atlas, R. C. Srivastava, and R. S. Sekhon, "Doppler radar characteristics of precipitation at vertical incidence," Reviews of Geophysics, vol. 11, no. 1, pp. 1-35, 1973.

[39] J. Janapati, B. K. Seela, P.-L. Lin et al., "Raindrop size distribution characteristics of Indian and Pacific Ocean tropical cyclones observed at India and Taiwan sites," Journal of the Meteorological Society of Japan. Ser. II, vol. 98, no. 2, pp. 299-317, 2020. 
[40] A. Tokay, D. B. Wolff, and W. A. Petersen, "Evaluation of the new version of the laser-optical disdrometer, OTT Parsivel2," Journal of Atmospheric and Oceanic Technology, vol. 31, no. 6, pp. 1276-1288, 2014.

[41] K. Friedrich, E. A. Kalina, F. J. Masters, and C. R. Lopez, "Drop-size distributions in thunderstorms measured by optical disdrometers during VORTEX2," Monthly Weather Review, vol. 141, no. 4, pp. 1182-1203, 2013.

[42] K. Friedrich, S. Higgins, F. J. Masters, and C. R. Lopez, "Articulating and stationary PARSIVEL disdrometer measurements in conditions with strong winds and heavy rainfall," Journal of Atmospheric and Oceanic Technology, vol. 30, no. 9, pp. 2063-2080, 2013.

[43] J. Jaffrain and A. Berne, "Experimental quantification of the sampling uncertainty associated with measurements from PARSIVEL disdrometers," Journal of Hydrometeorology, vol. 12, no. 3, pp. 352-370, 2011.

[44] T. Kozu and K. Nakamura, "Rainfall parameter estimation from dual-radar measurements combining reflectivity profile and path-integrated attenuation," Journal of Atmospheric and Oceanic Technology, vol. 8, no. 2, pp. 259-270, 1991.

[45] C. W. Ulbrich, "Natural variations in the analytical form of the raindrop size distribution," Journal of Climate and Applied Meteorology, vol. 22, no. 10, pp. 1764-1775, 1983.

[46] E. Adirosi, E. Volpi, F. Lombardo, and L. Baldini, "Raindrop size distribution: fitting performance of common theoretical models," Advances in Water Resources, vol. 96, pp. 290-305, 2016.

[47] C. Gatidis, M. Schleiss, C. Unal, and H. Russchenberg, "A critical evaluation of the adequacy of the gamma model for representing raindrop size distributions," Journal of Atmospheric and Oceanic Technology, vol. 37, no. 10, pp. 1765-1779, 2020.

[48] A. Zhang, J. Hu, S. Chen et al., "Statistical characteristics of raindrop size distribution in the monsoon season observed in southern China," Remote Sensing, vol. 11, no. 4, p. 432, 2019.

[49] G. Zhang, J. Vivekanandan, E. A. Brandes, R. Meneghini, and T. Kozu, "The shape-slope relation in observed gamma raindrop size distributions: statistical error or useful information?" Journal of Atmospheric and Oceanic Technology, vol. 20, no. 8, pp. 1106-1119, 2003.

[50] P. T. Willis, "Functional fits to some observed drop size distributions and parameterization of rain," Journal of the Atmospheric Sciences, vol. 41, no. 9, pp. 1648-1661, 1984.

[51] D. S. Torres, J.-D. Creutin, and J. D. Creutin, "A general formulation for raindrop size distribution," Journal of Applied Meteorology, vol. 33, no. 12, pp. 1494-1502, 1994.

[52] D. S. Torres, J. M. Porra, and J. D. Creutin, "Experimental evidence of a general description for raindrop size distribution properties," Journal of Geophysical Research, vol. 103, no. D2, pp. 1785-1797, 1998.

[53] J. Testud, S. Oury, R. A. Black, P. Amayenc, and X. Dou, "The concept of "normalized" distribution to describe raindrop spectra: a tool for cloud physics and cloud remote sensing," Journal of Applied Meteorology, vol. 40, no. 6, pp. 1118-1140, 2001.

[54] A. J. Illingworth and T. M. Blackman, "The need to represent raindrop size spectra as normalized gamma distributions for the interpretation of polarization radar observations," Journal of Applied Meteorology and Climatology, vol. 41, no. 6, pp. 286-297, 2002.

[55] H. Y. Lam, J. Din, and S. L. Jong, "Statistical and physical descriptions of raindrop size distributions in equatorial
Malaysia from disdrometer observations," Advances in Meteorology, vol. 2015, Article ID 253730, 14 pages, 2015.

[56] Z. Hu and R. C. Srivastava, "Evolution of raindrop size distribution by coalescence, breakup, and evaporation: theory and observations," Journal of the Atmospheric Sciences, vol. 52, no. 10, pp. 1761-1783, 1995.

[57] V. N. Bringi and V. Chandrasekar, Polarimetric Doppler Weather Radar: Principles and Applications, Cambridge University Press, Cambridge, UK, 2001.

[58] A. Nzeukou, H. Sauvageot, A. D. Ochou, and C. M. F. Kebe, "Raindrop size distribution and radar parameters at Cape Verde," Journal of Applied Meteorology, vol. 43, no. 1, pp. 90-105, 2004.

[59] J. S. Marshall and W. M. K. Palmer, "The distribution of raindrops with size," Journal of Meteorology, vol. 5, no. 4, pp. 165-166, 1948.

[60] R. A. Fulton, J. P. Breidenbach, D.-J. Seo, D. A. Miller, and T. O'Bannon, “The WSR-88D rainfall algorithm," Weather and Forecasting, vol. 13, no. 2, pp. 377-395, 1998.

[61] Q. Jin, Y. Yuan, H. J. Liu, C. E. Shi, and J. B. Li, "Analysis of microphysical characteristics of the raindrop spectrum over the area between the Yangtze river and the Huaihe river during summer," Acta Meteorologica Sinica, vol. 73, pp. 778-788, 2015, in Chinese.

[62] X. Y. Huang, J. N. Yin, and L. Ma, "Comprehensive statistical analysis of rain drop size distribution parameters and their application to weather radar measurement in Nanjing, China," Journal of the Atmospheric Sciences, vol. 43, pp. 691-704, 2019, in Chinese.

[63] Y. Wu and L. Liu, "Statistical characteristics of raindrop size distribution in the Tibetan Plateau and southern China," Advances in Atmospheric Sciences, vol. 34, no. 6, pp. 727-736, 2017.

[64] L. Ji, H. N. Chen, L. Li et al., "Raindrop size distributions and rain characteristics observed by a PARSIVEL disdrometer in beijing, northern China," Remote Sensing, vol. 11, no. 12, p. 1479, 2019.

[65] J. Vivekanandan, G. Zhang, and E. Brandes, "Polarimetric radar estimators based on a constrained gamma drop size distribution model," Journal of Applied Meteorology, vol. 43, no. 2, pp. 217-230, 2004.

[66] D. Brawn and G. Upton, "Estimation of an atmospheric gamma drop size distribution using disdrometer data," Atmospheric Research, vol. 87, no. 1, pp. 66-79, 2008.

[67] W.-Y. Chang, T.-C. C Wang, and P.-L. Lin, "Characteristics of the raindrop size distribution and drop shape relation in typhoon systems in the western Pacific from the $2 \mathrm{D}$ video disdrometer and NCU C-band polarimetric radar," Journal of Atmospheric and Oceanic Technology, vol. 26, no. 10, pp. 1973-1993, 2009.

[68] Y.-H. Chu and C.-L. Su, "An investigation of the slope-shape relation for gamma raindrop size distribution," Journal of Applied Meteorology and Climatology, vol. 47, no. 10, pp. 2531-2544, 2008.

[69] T. N. Rao, N. V. P. Kirankumar, B. Radhakrishna, and D. N. Rao, "On the variability of the shape-slope parameter relations of the gamma raindrop size distribution model," Geophysical Research Letters, vol. 33, no. 22, Article ID L22809, 2006. 